\title{
Didáctica de la imagen: de material de apoyo a lenguaje para la mediación pedagógica en los ambientes de aprendizaje con tecnologías
}

\author{
Alma Elisa Delgado Coellar, Universidad Nacional Autónoma, México \\ Erika Robledo Ramírez, Universidad Nacional Autónoma, México \\ Huberta Márquez Villeda, Universidad Nacional Autónoma, México
}

\begin{abstract}
Resumen: La imagen es un elemento simbólico que indudablemente inunda nuestro entorno en todos los ámbitos, sobretodo en áreas como el entretenimiento, la publicidad, los medios de comunicación, etc. Su potencial es infinito en cada uno de los campos desde el que se estudie, esto debido a su configuración, que genera un lenguaje de comunicación visual a partir del cual el hombre intaractúa entre sí y con su contexto. Así, la imagen como producto comunicativo ha sido la guardiana y transmisora del conocimiento desde tiempos inmemoriales, como los jeroglificos egipcios, por poner un claro ejemplo. Desde el campo educativo, la imagen ha estado inmersa en diversos materiales y recursos didácticos como libros de texto, guías, esquemas, manuales, etc., sin embargo, su papel ha sido el de apoyo en los recursos para el aprendizaje y no el de instrumento de mediación pedagógica en todo el proceso de enseñanza-aprendizaje. Por tal motivo, en el presente, se expone un planteamiento reivindicador para potencializar el cáracter didáctico de la imagen. Es posible abordar los estudios de la didáctica de la imagen con este enfoque, gracias a los nuevos entornos de aprendizaje propiciados por las tecnologías digitales, en las que las interfaces gráficas (construidas y configuradas por lenguajes visuales), constituyen precisamente el elemento didáctico de mediación pedagógica entre los actores: alumnosprofesores (usuarios), contenidos y tecnologías para el aprendizaje (interfaces gráficas - objeto), instituciones educativas y contexto (entorno), proceso de enseñanza-aprendizaje (acción pedagógica). Así, a partir del análisis de los componentes, la comunicación educativa, configuración visual, diseño y significación de la imagen didáctica son elementos de mediación pedagógica en los procesos de enseñanza-aprendizaje mediados por tecnologías digitales, en las que actúan como vehículo o medio los recursos didácticos digitales.
\end{abstract}

Palabras clave: aprendizaje en línea, mediación pedagógica, didáctica de la imagen, tecnologías educativas, recursos didácticos ditigales

\begin{abstract}
The image is a symbolic element that certainly fills our environment in all areas, especially in areas such as entertainment, advertising, media, etc. Its potential is infinite in each of the fields from which you study this because of their configuration, generating a visual language of communication from which the man intaractúa each other and with their context. Thus, the image as communicative product has been the guardian and transmitter of knowledge since time immemorial, as Egyptian hieroglyphics, to give a clear example. From the educational field, the image has been involved in various materials and educational resources such as textbooks, guides, charts, manuals, etc., however, their role has been to support resources for learning and not to pedagogical mediation instrument in the whole process of teaching and learning. Therefore, in the present an approach reivindicador exposed to potentiate the didactic nature of the image. It is possible to approach the study of the teaching of the image with this approach, thanks to new environments learned-zaje brought about by digital technologies, in which the graphical interfaces (built and configured by language-jes visual), are precisely the didactic element of pedagogical mediation between actors: student-teachers (users), content and learning technologies (GUIs - object), educational institutions and context (environment), teaching-learning process (pedagogical action). Thus, from the analysis of up-tes, educational communication, visual configuration, design and significance of teaching image are elements of pedagogical mediation in the teaching-learning mediated by digital technologies, which act as a vehicle or means digital teaching resources.
\end{abstract}

Keywords: Online Learning, Teaching Mediation, Didactic Image, Educational Technologies, Teaching Resources Ditigales

Revista Internacional de Tecnologías en la Educación

Volumen 3, Número 2, 2016, <http://sobrelaeducacion.com>, ISSN 2386-8384

(C) Global Knowledge Academics. Alma Elisa Delgado Coellar et al.

Todos los derechos reservados. Permisos: soporte@gkacademics.com 
"Todo lo que existe es imagen. Todo se traslada a un terreno estético y se valora por su apariencia; todo ha sido transformado en ARTE".

Neil Leach

\section{Introducción}

$\mathrm{G}$ racias al avance de las tecnologías digitales y el crecimiento de los nuevos medios de comunicación derivados de las mismas, como las redes informacionales (internet), estamos cada momento más expuestos a una infinidad de mensajes que involucran a la imagen como fundamento simbólico de la comunicación digital, a través de las interfaces gráficas de los dispositivos tecnológicos, como: computadoras, telefonía móvil, tabletas, smart TV, etc.

Así, las tecnologías digitales nos plantean un nuevo desafío en diversos escenarios de la cultura contemporánea, denominada por muchos autores como sociedad de la información, puesto que habitan nuestra cotidianidad y van construyendo significados a través de lenguajes visuales y sus características al estar contenidos en los dispositivos digitales, como: interactividad, hipertextualidad, multimedia, conectividad y la virtualidad. Estás características permiten comunicarnos con una diversidad de posibilidades que amplían nuestros procesos de percepción-cognición y representación simbólica. Estas transformaciones derivadas de los avances científicos y tecnológicos inciden de forma directa en los procesos de construcción del pensamiento. Por ello, atraviesan la construcción de conocimientos y saberes en el contexto de las prácticas educativas.

Las ciencias de la educación, en general, se anclan en la facultad humana para generar, transmitir y recibir estímulos en la memoria y, sobre todo, en la capacidad intelectiva. Estos estímulos provienen de diversas fuentes y entran a través de los sentidos, sin embargo, los de mayor impacto en aprendizaje, provienen de los estímulos visuales y auditivos, que se materializan a partir de los recursos didácticos o materiales educativos. A partir de esto, destaca la importancia de la imagen (dinámica y estática), como elemento clave, es decir, la materia prima de los lenguajes visuales en el contexto educativo, y por lo tanto de la comunicación visual, para actuar como lenguaje didáctico.

De esta forma, la incidencia de las tecnologías digitales en la educación y su relación con la imagen, no trata solamente de la aparición de nuevas tecnologías al servicio educativo, sino de un proceso de cambio en la educación y en la conceptualización de la imagen como elemento didáctico y vehículo de mediación pedagógica en los procesos de enseñanza-aprendizaje basados en tecnologías digitales.

\section{Comunicación y medios educativos}

La modificación de conductas afectivas, psicomotrices y cognoscitivas, se efectúa a través de procesos de enseñanza-aprendizaje y el proceso de enseñanza-aprendizaje consiste, fundamentalmente, en un conjunto de transformaciones sistemáticas de los fenómenos en general, sometidos éstos a una serie de cambios graduales cuyas etapas se producen y suceden en orden ascendente, de aquí que se la deba considerar como progresivo, en constante movimiento y dinámico. Como consecuencia del proceso de enseñanza-aprendizaje, tienen lugar cambios sucesivos e ininterrumpidos en la actividad cognoscitiva del individuo (alumno) con la participación del docente en su labor conductora u orientadora para el dominio de conocimientos, habilidades, hábitos y conductas. Es decir que, la esencia de este proceso, está en la transmisión de información mediante la comunicación directa o apoyada en la utilización de medios auxiliares o recursos didácticos, de mayor o menor grado de complejidad.

Cabe señalar, que existen diversas estrategias de enseñanza-aprendizaje. Campos (2000) señala seis categorías: 1) Estrategias para propiciar la interacción con la realidad, la activación de conocimientos previos y generación de expectativas. 2) Estrategias para la solución de problemas 
y abstracción de contenidos conceptuales. 3) Estrategias para la organización de información nueva. 4) Estrategias para el logro de la permanencia de los conceptos. 5) Estrategias para la transferencia de conocimiento. 6) Estrategias para la conformación de comunidades. Esta clasificación de estrategias de enseñanza-aprendizaje, requiere en todos sus tipos de los recursos didácticos o materiales para coaccionarse en el proceso educativo.

Según Rodríguez Diéguez (1978), la enseñanza es el estímulo externo que pretende regir un aprendizaje sistemático y, éste, supone la presencia de dos componentes básicos: una acción física del medio exterior sobre el sujeto, y un correlato psíquico que recibe el estímulo. Estos dos componentes, físico y psíquico, son los que caracterizan, para Couffignal (1970), una información. Así, el proceso en el que determinados estímulos físicos provocan determinadas situaciones psíquicas, es la operación informacional que llamamos comunicación, la cual se encuentra correlacionada con el proceso de aprendizaje.

La comunicación está dada en el ser humano de manera natural, es a través de ella que se transfiere y asimila la información (que se da a través de estímulos físicos y psíquicos, como se detalló previamente). Es decir, con la transferencia de significados se difunde la información, los pensamientos, las ideas y opiniones. De aquí radica su importancia para el desarrollo humano individual y colectivo, ya que el hombre se comunica para influir y afectar intencionalmente sobre el contexto, es decir, que toda conducta de comunicación tiene por objeto producir una determinada respuesta por parte de un determinado público. Así, las funciones de la comunicación dependen del enfoque y el área del conocimiento desde donde se observen y en el campo educativo son de gran importancia sus contribuciones, ya que se han analizado a lo largo de la historia diversos modelos comunicativos cuya aplicación se da directamente en relación al proceso de enseñanza.

Por otro lado, los recursos, también conocidos como medios o material didáctico, son: "Los materiales de que se dispone para conducir el aprendizaje de los alumnos" (Mattos, 1963). Por su lado, Zabala (1990) incorpora el concepto de materiales curriculares como "los instrumentos y medios que proveen al educador de pautas y criterios para la toma de decisiones, tanto en la planificación como en la intervención directa del proceso de enseñanza".

Se debe entender, en primera instancia, que existen diferencias entre los términos y que en muchas ocasiones son utilizados sin realizarse un examen concreto de lo que refieren. Así, para Moreno (2004), el término recurso engloba, a los términos de medio y material didáctico.

Podríamos decir que recurso es una forma de actuar, o más bien la capacidad de decidir sobre el tipo de estrategias que se van a utilizar en los procesos de enseñanza; es, por tanto, una característica inherente a la capacidad de acción de las personas. Los medios didácticos podríamos definirlos como el instrumento del que nos servimos para la construcción del conocimiento; $y$, finalmente, los materiales didácticos serían los productos diseñados para ayudar en los procesos de aprendizaje. (Moreno, 2004, p. 3)

Para autores como Gimeno Sacristán (1981) "los medios como recursos instrumentales (herramientas o vehículos) hacen referencia a un material didáctico de todo tipo, desde los materiales del entorno a cualquier recurso audiovisual, ordenadores, etc. Así, el recurso didáctico no es la experiencia directa del sujeto ante el conocimiento, sino una determinada modalidad, simbólicamente codificada, de dicha experiencia”.

Con esto se observa que el concepto de recurso didáctico es amplio e implica diversos elementos, que de manera conjunta constituyen un factor clave dentro del proceso de enseñanzaaprendizaje, ya que su función es aumentar la efectividad del trabajo pedagógico y elevar la motivación hacia la absorción del conocimiento, así como la generación de aprendizajes significativos, porque objetivan la enseñanza, activan las funciones cognitivas, produciendo en los alumnos comprensión, reflexión y asimilación de la información curricular. Y es, en estos recursos didácticos, en donde, el lenguaje visual, cobra vital importancia, para cumplir con el objeto de ser elemento de mediación pedagógica y se logre el objetivo último de la enseñanza: el aprendizaje. 
Gráfico 1: Marco de los recursos didácticos

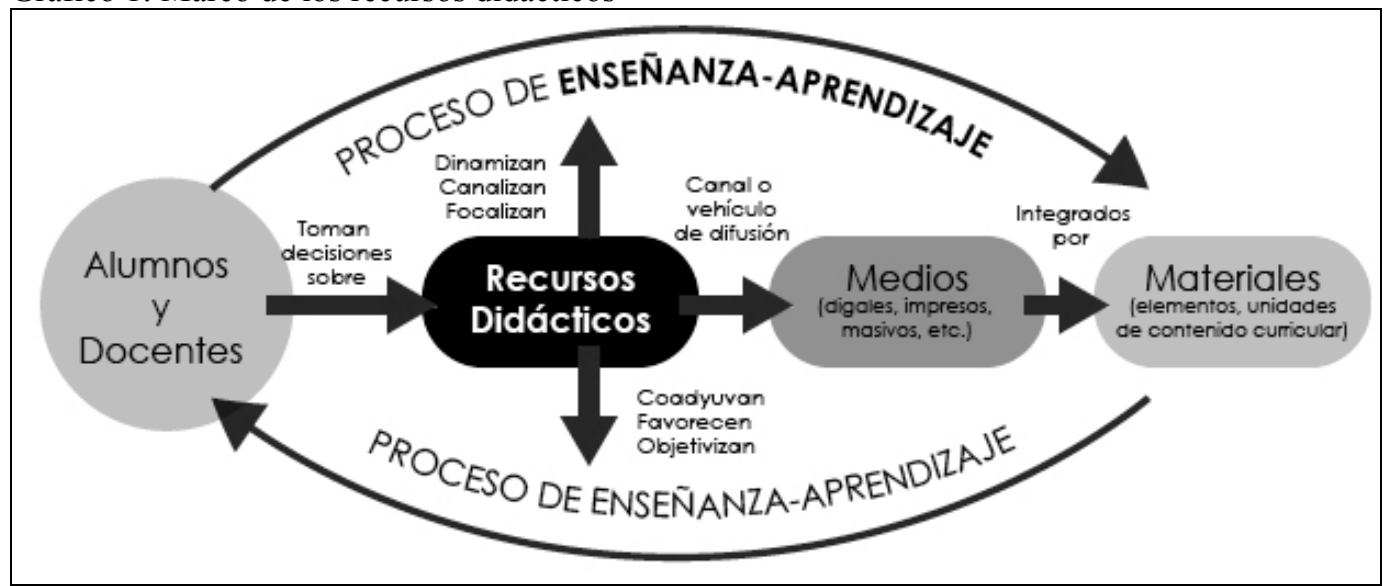

Fuente: Delgado, A. (2016).

Como se observa en el gráfico, una cuestión indudable de los recursos didácticos es que generan interacción entre los componentes del proceso de enseñanza-aprendizaje. López (1981) en referencia a los materiales educativos señala entre sus características, la posibilidad de permitir la experimentación con modelos análogos a la realidad, simbolizar y abstraer relaciones entre conceptos, asi como proveer medios para ejercitar o evaluar nuevos aprendizajes.

En la selección de los recursos didácticos a utilizar, se debe tener presente, que estos fungirán como medium en donde participa el conocimiento curricular, los lenguajes de comunicación (textual, visual, auditivo, espacial), para lograr una comunicación educativa efectiva. Para Gimeno Sacristán (1981) el valor pedagógico de los recursos didácticos está íntimamente relacionado con el contexto en que se usan, más que en sus propias cualidades y posibilidades intrínsecas. Así, la inclusión de los recursos didácticos en un determinado contexto educativo exige que los docentes tengan claro cuáles son las principales funciones que pueden desempeñar los medios en el proceso de enseñanza-aprendizaje. Entre las principales funciones:

1. Función innovadora. Cada nuevo tipo de recursos plantea una nueva forma de interacción. En unas ocasiones provoca que cambie el proceso, en otras refuerza la situación existente.

2. Función motivadora. Se trata de acercar el aprendizaje a los intereses de los aprendices y de contextualizarlo social y culturalmente.

3. Función estructuradora de la realidad. Al ser los recursos mediadores de la realidad, el hecho de utilizar distintos medios facilita el contacto con distintas realidades, así como distintas visiones y aspectos de las mismas.

4. Función configuradora de la relación cognitiva. Según el medio, el tipo de operación mental utilizada será diferente.

5. Función facilitadora de la acción didáctica. Los recursos facilitan la organización de las experiencias de aprendizaje, actuando como guías, no sólo en cuanto ponen en contacto con los contenidos, sino también en cuanto que requieren la realización de un trabajo con el propio medio.

6. Función formativa. Los distintos medios permiten y provocan la aparición y expresión de emociones, informaciones y valores que transmiten diversas modalidades de relación, cooperación o comunicación. 


\section{Didáctica de la imagen}

Para adentrarnos en las características de la imagen como elemento didáctico y como parte del fenómeno educativo al ser instrumento de mediación pedagógica, aunado al entendimiento del proceso comunicativo, es pertinente aclarar, en primera instancia, los elementos básicos de nuestro sistemas de percepción visual, el cual, es un fenómeno natural, y que puede transformarse a un fenómeno cultural, desde que seleccionamos a través de filtros cognitivos, categorías y hábitos, la información visual, para posteriormente generar un proceso interno de estructura y dotación de significado.

En este sentido, la imagen (componente básico del lenguaje visual) ha tenido y tiene una función comunicativa como ente de transmisión, identidad, cohesión humana y de difusión de la cultura; en el ámbito educativo es favorecedora en el proceso de enseñanza-aprendizaje por su naturaleza didáctica, lúdica y sintetizadora de significados, contenidos y en la correlación de conceptos. De esta forma, el lenguaje visual permite vincular los contenidos del conocimiento en los diversos campos de estudio del hombre, a través de la comunicación educativa para potencializar y fortalecer los procesos de enseñanza-aprendizaje, no sólo como instrumentos o medio de interpretación a partir de las diferentes tipologías de recursos didácticos, sino como elemento de mediación pedagógica.

Según González Ochoa (1986), "la visión humana no es un simple reflejo neurológico de una cadena casual que empieza con un haz de luz sobre el ojo, aunque esto sea una condición necesaria para la visión, sino que la visión humana es algo construido, es producto de nuestro propio hacer; es un artefacto histórico y cultural, creado y transformado por nuestros propios modos de representación". Es decir que la visión en un sentido estricto, es histórica y culturalmente variable, es un artefacto cultural producto de los lenguajes, los mitos, el arte, la historia, etc.

La imagen, como producto del proceso de percepción visual del hombre es un signo visual. El signo para Peirce es "algo que está para alguien en lugar de otra cosa". Lo que significa que un signo es una representación mental a través de la cual alguien (individuo) puede conocer los objetos de la realidad. Julieta Haidar (1995) distingue varias posturas en los estudios del signo de acuerdo con categorizaciones basadas en la relación de este con el mundo, establecidas de la siguiente manera: el signo sustituye a la realidad; el signo representa a la realidad; el signo refleja a la realidad; el signo refracta a la realidad; el signo indica a la realidad; y el signo construye a la realidad.

De esta forma, el signo visual, contiene una fuerte carga significativa y un determinado nivel de iconicidad que conforme va disminuyendo a su vez, va aumentando el grado de abstracción del signo visual. Así, una imagen se define por tres hechos que conforman su naturaleza:

a) Una selección de la realidad sensorial;

b) Un conjunto de elementos y estructuras de representación específicamente icónicas;

c) Una sintaxis visual.

Existen a su vez, diversos criterios para clasificar las imágenes, algunos de los principales son: por el tipo de soporte que la contiene y por su legibilidad (mayor o menor dificultad para "leer" la información visual).

De esta manera, lo que denominamos signos visuales, no son sino la abstracción, la representación de los elementos de la realidad que gracias a nuestra capacidad de simbolizar, entendemos y otorgamos un significado de acuerdo con nuestros contexto histórico socio-cultural. Como signo, lo visual -la imagen- actúa entre sí, a través de conexiones, combinaciones, correlaciones y configuración en diversos niveles de interrelación. 


\section{Iconicidad e imagen}

El icono es una unidad discursiva (de contenido) y se caracteriza por guardar cierta semejanza con su referente. Así, el término iconicidad es utilizado para los estudios de la imagen y está unido con la noción de "imitación" de la naturaleza; por lo que, el tratamiento de la imagen ha considerado la "semejanza" como su rasgo más característico. Sin embargo, definir la imagen por su relación con la "realidad" es delimitar su naturaleza de signo con una relación arbitraria entre un plano sensible y otro inteligible.

Greimas (s.f) propone que hablar de iconicidad es hablar de "ilusión referencial", es decir, del resultado de un conjunto de procedimientos discursivos que operan sobre la concepción muy relativa de lo que cada cultura concibe como la realidad (lo que es semejante para una cultura o época, no es semejante para otra). Por lo tanto, la iconización no es una facultad que pertenezca a las imágenes sino que es un fenómeno semiótico, cambiante y modificable. Por su lado, D.A. Dondis (1976) clasifica en tres niveles fundamentales la iconicidad de las imágenes:

I. Representativo: donde la percepción directa por parte del receptor del referente visual se establece desde un nivel de codificación bajo.

II. Simbólico: establece una mayor simplicidad en la representación de la imagen referencial que así contiene, codificada con mayor complejidad.

III. Abstracto: reduce la imagen a sus componentes visuales más básicos, es el nivel de codificación más alto.

Sin embargo, otros autores como Villafañe y Mínguez (1996) proponen una escala de iconicidad basada en la semejanza entre la imagen y su referente. La escala está construida de mayor a menor grado y en cada salto de nivel suponen que la imagen pierde algunas de las propiedades sensibles de la iconicidad. Cabe señalar que su propuesta se enfoca en la imagen fija o estática, y para clarificar estás características icónicas de la imagen, a continuación se ilustran los niveles de iconicidad:

Figura 1: Niveles de Iconicidad según Villafañe
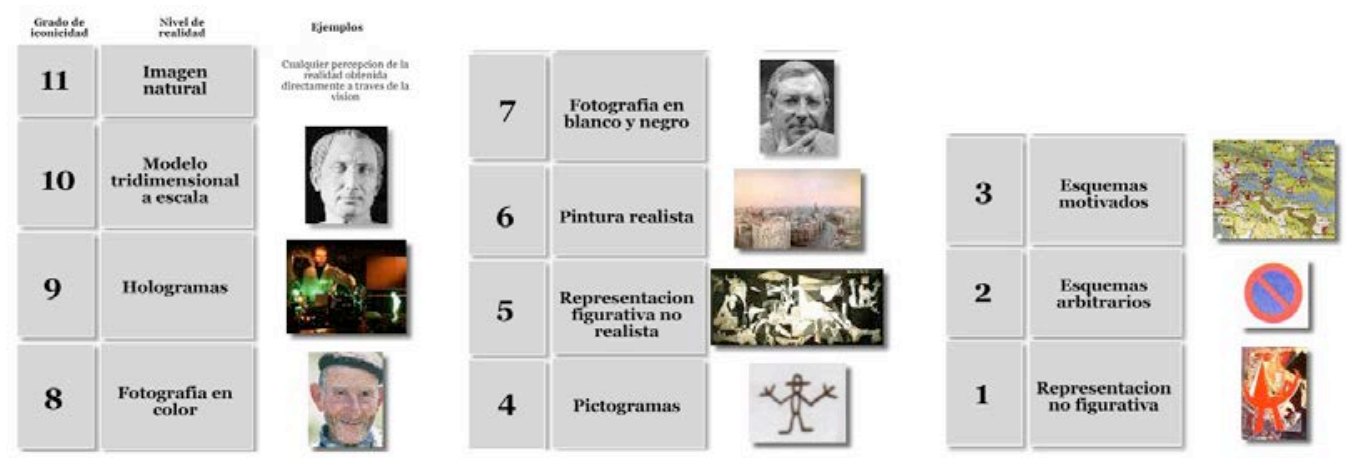

De esta forma, la utilización de determinado grado de iconicidad como recurso discursivo en la creación de una imagen, dependerá de la función con la que se pretenda usar, en el caso de nuestro estudio, para los contextos educativos y como recurso didáctico. Pero para determinar el grado de iconicidad a utilizar en los materiales didácticos en donde se implemente la imagen como instrumento de mediación pedagógica, se deben considerar no sólo los niveles de iconicidad, sino los objetivos de aprendizaje, la modalidad educativa, el tipo de medio (tradicional o digital) a utilizar, la institución educativa, la naturaleza y tipo de conocimiento, entre otros factores. Esto determinará distintos tipos de imágenes didácticas como: imágenes de reconocimiento, descriptivas, informativas o artísticas, entre otras. 


\section{El acto didáctico y el signo visual}

Titone (1968) define al acto didáctico como: "la acción intencional del maestro en el momento en que establece una relación bipolar activa, que se actualiza en un proceso dialéctico personal, que comienza en el estímulo magistral transeúnte (enseñanza), para terminar en la respuesta inmanente asimiladora de una verdad (aprendizaje) por parte del alumno". Y, a la enseñanza como: "el acto de causar la reproducción de la ciencia por parte del alumno mediante el estímulo adecuado del mensaje lingüístico".

De estos conceptos podemos dilucidar que del docente procede el estímulo de enseñanza y en el discente o alumno, recae la asimilación del saber, es decir, el aprendizaje. Estos estímulos de enseñanza a los que se refiere, pueden ser objetos, imágenes, comportamientos, -signos- que según Barthes (1971) "pueden significar y significar ampliamente, pero no de un modo autónomo... sino que tienen que ver con el lenguaje". Según Saussure, el lenguaje es un sistema constituido por dos factores la langue (lengua) que puede concebirse como una alacena comunitaria que alberga todos los diferentes signos posibles, y la parole (habla) que es el acto de la construcción y utilización de la lengua. Desde su punto de vista, el lenguaje es un sistema abstracto, en donde la lengua es la que relaciona con las restricciones de combinación y sustitución a los signos. De aquí que el signo sea un aspecto de excepcional interés en la educación, como se ha revisado.

Por otro lado, el proceso de enseñanza-aprendizaje, cuyo objetivo es la transmisión del conocimiento, es un acto sémico, es decir, un acto de codificación y decodificación de signos que se generan a partir de lenguajes visuales, auditivos, textuales, etc., por parte de los actores, profesor y alumno. Este acto sémico, implica distintos niveles de asimilación o dominio de las áreas cognitivas, afectivas y psicomotrices de los sujetos. En el dominio cognitivo se generan así, los siguientes grados de complejidad cognitiva de modo ascendente, según Benjamín Bloom, (psicólogo de la educación de la Universidad de Chicago): información, comprensión, aplicación, análisis, síntesis y evaluación. En el dominio afectivo: toma de conciencia, respuesta, valorización, organización y caracterización. Y en el dominio psicomotor se clasifica en las destrezas que pueden variar en frecuencia, energía y duración, generando los siguientes niveles: percepción, disposición, respuesta dirigida, respuesta automática y ejecución consciente. Estos actos sémicos que implican diferentes grados de asimilación cognitiva, tienen como elemento base a los signos -que conforman lenguajes- y cuando hablamos de signos visuales, nos referimos a símbolos, íconos e índices.

Se denomina símbolo a toda imagen, figura o divisa que posee una significación convencional de acuerdo a un contexto socio-cultural. En términos semióticos, el símbolo es un signo que, de acuerdo a la clasificación de Pierce, posee siempre una relación por convención arbitraria entre significado y significante, a diferencia del ícono cuya relación es de semejanza y el índice, caracterizado por la causalidad. El símbolo, en cuanto implica un referendo abstracto, supone un nivel de elaboración más elevado. El símbolo constituye un instrumento fundamental, por cuanto supone la posibilidad de ir perdiendo el lastre progresivo con un referendo en concreto y facilitar el proceso de abstracción. De esta forma, en el contexto del acto sémico con finalidad didáctica, se pueden señalar, según Rodríguez Diéguez (1978), por lo menos tres tipos de símbolos que facilitan el proceso de asimilación del conocimiento a partir de la imagen:

1. La metáfora visual. Que supone presentar un símbolo en cuya clave perceptiva existe información que permite la asociación con el término metaforizado y al cual se aplican las características del término metafórico.

2. Los procesos de atribución conceptual (metonimia). Estos giran en torno a una idea central y pueden llevar a una elaboración simbólica posterior, en la que se presenta una imagen concreta en representación de una estructura conceptual, buscando, como en la alegoría literaria, una relación de correspondencia entre los elementos de la composición simbólica y la base conceptual que la sustenta y es previa. 
3. Signos sustitutivos sensu stricto. Que presentan una superposición de imágenes, generalmente relacionales de carácter simbólico.

De la articulación, interacción y estructura producida por estos símbolos, surge lo que Cirlot (1969) denomina como sintaxis simbólica. El refiere que en cualquiera de sus apariciones, los símbolos no suelen presentarse aislados, sino que se unen entre sí, dando lugar a las composiciones simbólicas, ya sea desarrolladas en el tiempo (relatos), en el espacio (obras de arte, emblemas, símbolos gráficos) o en el espacio y el tiempo (sueños, formas dramáticas). La asociación de estos elementos combina significados, y estás asociaciones son las que originan dicha sintaxis simbólica.

La sintaxis simbólica puede proceder, en lo que respecta a la conexión de sus elementos individuales en cuatro maneras: 1) modo sucesivo (colocación de un símbolo al lado de otro; sus significados no se combinan, ni siquiera se relacionan entre sí); 2) modo progresivo (los significados de los símbolos no se alteran mutuamente, pero representan las distintas etapas de un proceso); 3) modo compositivo (los símbolos se modifican por su vecindad y dan lugar a significados complejos, es decir se produce combinación y no mezcla de sus sentidos); 4) modo dramático (interacción de los grupos; se integran todas las posibilidades de los grupos anteriores).

\section{La imagen como elemento de mediación pedagógica en ambientes de apren- dizaje con tecnologías digitales}

Hablar de mediación es hablar de distancia, es decir, que deben existir dos o más elementos separados que requieren de un medio o canal de regulación e interacción. El concepto de mediación, por lo tanto, implica acción, intervención, proceso de transferencia y construcción, ya que los medios por sí mismos no generan mediación, al ser soportes o vehículos que registran, almacenan, codifican y decodifican, en sí, transladan información. Sin embargo, estos medios, recursos o elementos, adquieren el lugar de instrumentos de mediación pedagógica, al convertirse en vehículos de intercomunicación en la reconstrucción de procesos cognitivos para el aprendizaje. De esta forma, la mediación pedagógica de los recursos permite una relación entre los elementos del acto educativo con la finalidad de obtener un proceso de interactividad (mutua transferencia).

Por otro lado, estamos claros que en el contexto contemporáneo, la digitalización es la característica principal de los diversos contenidos que produce el hombre, de esta manera, la imagen, sonidos, símbolos, documentos, etc., son virtualizados, es decir, llevados a soportes digitales para ser compartidos o redistribuidos a diversos usuarios y con distintas finalidades. En el campo educativo, hemos revisado el papel de la imagen como elemento de comunicación visual, y esta, también ha migrado hacía el ámbito digital, teniendo así una gran variedad de formatos y características en su modo estática y dinámico.

\section{Mediación pedagógica}

La mediación implica el acercamiento de instrumentos (herramientas, signos) que permiten el desarrollo de procesos mentales que inician con una actividad compartida entre el niño y un adulto (sujeto mediador) y construyen procesos internos y externos (procesos de mediación).

Según Medrano (2009), existen diversos criterios de mediación que fundamentalmente desencadenan las reconstrucciones y transformaciones de cada sujeto con relación a diversas necesidades de su diversidad cultural y social.

De acuerdo a lo anterior, podemos enterder que existen diversos elementos como: ambiente socio-cultural, la interacción con otros sujetos, herramientas de trabajo, recursos, materiales, tecnologías, etc., y no únicamente la figura del profesor como mediador pedagógico. Es decir, que en el acto educativo, encontramos diversos componentes que funcionan como mediadores, y que, para el análisis de la acción de cada uno de estos, debemos considerar una serie de criterios 
de mediación que nos permitan entender su funcionamiento como instrumento de mediación pedagógica.

Para Gutiérrez y Prieto (1999), la mediación pedagógica, "se ocupa del sentido del acto educativo y éste consiste en seres humanos que se relacionan para enseñar y aprender. Es la ciencia de esa relación (...). Cuando uno se asume como educador lo hace como un ser de relación y la pedagogía se ocupa del sentido de esa relación" (pp. 5-6). Esta idea de mediación pedagógica implica concebir a los sujetos de la enseñanza y del aprendizaje como interlocutores activos en la búsqueda y construcción del sentido. Sin embargo, esta idea de mediación -como se ha revisado, se limita a referir una relación únicamente entre los sujetos (profesor-alumno) y deja de lado a los demás factores del acto educativo, como el contexto, el currículo, las estrategias de enseñanza-aprendizaje, la modalidad educativa y los recursos didácticos, las herramientas, medios y materiales, entre otros mencionados.

Para ampliar el concepto de mediación pedagógica de acuerdo a las modalidades educativas, Gutiérrez y Prieto (1999), señalan que: "En la relación presencial, la mediación puede surgir del trabajo en el aula y depende casi siempre de la capacidad y la pasión del docente. En un sistema a distancia los materiales encarnan esa pasión y son ellos los que permiten al estudiante encontrar y concretar el sentido del proceso educativo" (p.10). Así, extienden su concepto de mediación pedagógica, considerando "el tratamiento de contenidos y de las formas de expresión de los diferentes temas a fin de hacer posible el acto educativo, dentro del horizonte de una educación concebida como participación, creatividad, expresividad y relacionalidad" (Gutiérrez y Prieto, 1999, p. 9).

Así, el proceso de mediación se caracteriza fundamentalmente por ser un proceso intencionado y de reciprocidad, además genera una experiencia significativa que trasciende el aquí y ahora, lo que exige entre otras cosas la regulación (control) de la impulsividad. La mediación como proceso, requiere además, de autoevaluación de parte de los sujetos que aprenden. Exige también controlar el esfuerzo individual y colectivo y tener presente etapas (procesos) y resultados. Todo proceso de mediación parte de la premisa de que es posible la modificabilidad cognitiva y también afectiva del sujeto y que ésta se propicia en la interrelación.

En resumen, la mediación es un estilo de interacción educativa no frontal ni impuesta aunque sí intencionada, consciente, significativa y trascendente (Ferreiro, s.f.). Es acción recíproca entre al menos dos elementos que comparten una experiencia de aprendizaje y en donde una de ellos (el mediador) coadyuva a otros elementos (en este caso, sujetos), a moverse en su zona de desarrollo potencial dando su contribución para que encuentren el sentido y significado a lo que hacen y quieran lograr en el aprendizaje. De esta forma, el concepto de mediación pedagógica es central en el fenómeno educativo, porque interrelaciona a todos los elementos en diversas formas, grados de interacción y para las diversas modalidades educativas (presencial, a distancia y mixta). Igualmente, la interacción es un componente clave en la mediación pedagógica, ya que de acuerdo al grado de relación entre los elementos se puede o no propiciar el proceso de enseñanzaaprendizaje.

\section{La imagen como instrumento de mediación pedagógica}

En este proceso de enseñanza-aprendizaje la imagen, como hemos revisado con anterioridad, actúa precisamente como vehículo de mediación pedagógica, a partir de la cual se transmiten los contenidos, actividades de aprendizaje, medios de evaluación, etc. Históricamente, la imagen ha servido de apoyo para aumentar la efectividad del trabajo pedagógico y para elevar la motivación hacia la absorción del conocimiento, ya que, reducen el tiempo dedicado al aprendizaje porque objetivan la enseñanza y activan las funciones intelectuales y cognitivas, además, de ayudar a garantizar la asimilación esencial de la información para los andamiajes de un aprendizaje significativo.

Así pues, aunadas las estrategias pedagógicas de enseñanza con las imágenes aplicadas en diversos materiales, recursos o medios didácticos acordes al tipo de contenido, se generan los elementos necesarios para producir en el alumno la observación, comprensión, reflexión, asimi- 
lación del conocimiento, etc., según sea el objetivo educativo. Para autores como Gimeno Sacristán (1981) "los medios como recursos instrumentales hacen referencia a un material didáctico de todo tipo, desde los materiales del entorno a cualquier recurso audiovisual, ordenadores, etc. Así, el recurso didáctico no es la experiencia directa del sujeto ante el conocimiento, sino una determinada modalidad, simbólicamente codificada, de dicha experiencia".

Finalmente, la imagen para constituirse como instrumento de mediación pedagógica, debe considerarse una planeación específica, selección, determinación de grados de iconicidad, una manera de abordar la información y darle forma -diseñarla, estructurarla-, con la finalidad de integrar en ella distintos elementos gráficos (color, texturas, grados e iconicidad, etc.), de manera que dejen de ser vehículos (meros conductos), y se transformen en elementos de mediación, que como se ha expuesto, implica intervención, intención, transformación y acción para el aprendizaje. Como refiere Valdés:

[...] La estructura de mediación se diversifica de acuerdo a la situación en la que se encuentran los sujetos y pone en acción componentes que permiten a estos, aprender y enseñar, componentes como son los tecnológicos, didácticos, pedagógicos (explícitos, implícitos, formales, informales, etc.), todos relacionados en una compleja dinámica situacional y multimedial [...]. (Valdés, 2005, p. 121)

\section{Conclusión}

La imagen es constructora de significado desde tiempos ancestrales y en el campo educativo ha estado inmersa en todos los sentidos y sobretodo como parte de los recursos o materiales didácticos, sin embargo su potencial ha sido explotado más recientemente debido al uso de las tecnologías digitales y los nuevos ambientes de aprendizaje, en donde su representación y estudio como instrumento de mediación pedagógica en los ambientes educativos basados en tecnologías digitales es fundamental, ya que en las interfaces gráficas de estas tecnologías es en donde ocurren los procesos de enseñanza-aprendizaje.

Este proceso es un acto sémico, en el que la imagen, como signo visual, significa de acuerdo al grado de iconicidad o abstracción en el que fue utilizado, y por lo tanto construye aunado a otros signos visuales un lenguaje, que permite comunicar estructuras complejas de conocimiento. Esta codificación a partir del lenguaje visual, puede ser observada en la interfaz gráfica de una pantalla de cómputo, Smart Tv, dispositivo móvil, consola de videojuego, etc., que son instrumentos para la comunicación digital. Así, cuando se abordan temáticas relacionadas con el aprendizaje mediado por tecnologías digitales (Objetos de Aprendizaje, Plataformas E-learning; Multimedia educativo; software; simuladores de aprendizaje; etc.), el uso de los componentes sintácticos del lenguaje visual, su instrumentación y orden semántico, son herramientas fundamentales para la mediación pedagógica en el proceso de enseñanza-aprendizaje, ya que configuran estructuras complejas de significado a partir de recursos didácticos específicos que fungen como el vehículo o medio a partir del cual cumplen su función. Dentro de estos recursos, se esquematizan en: mapas conceptuales, infografías, líneas de tiempo, esquemas, ilustraciones, representaciones isométricas, videos, multimedia, etc. 


\section{REFERENCIAS}

Barthes, R. (1971). Elementos de Semiología. Madrid, España: Editor Alberto Corazón.

Campos, Y. (200). Estrategias de Enseñanza-Aprendizaje. México.

Cirlot Laporta, J. E. (1969). Diccionario de símbolos. Barcelona, España: Editorial Labor.

Costa, J. (1998). La esquemática. Barcelona, España: Editorial Paidos.

Diéguez Rodríguez, J. L. (1978). Las funciones de la imagen en la enseñanza. Semántica y Didáctica. Barcelona, España: Editorial Gustavo Gili.

Dondis, A. (1976). La Sintaxis de la Imagen. Introducción al alfabeto visual. Barcelona, España: Editorial Gustavo Gili.

Ferreiro, R. y DeNapoli, A. J. (s.f.). Un concepto clave para aplicar exitosamente las tecnologías de la educación: los nuevos ambientes de aprendizaje. Revista Panamericana de Pedagogía.

González Ochoa, C. (1986). Imagen y sentido. Elementos para una semiótica de los mensajes visuales. En: Cuadernos del Seminario de Poética 9. México: Universidad Nacional Autónoma de México.

Haidar, J. (1995). Semiótica (1er curso). Apartado: El campo de la Semiótica Visual. México: Universidad Autónoma Metropolitana.

Maldonado, T. (2007). Memoria y conocimiento. Sobre los destinos del saber en la perspectiva digital. Editorial Gedisa.

Medrano, I. (2009). La mediación pedagógica en las competencias para la vida en el desempeño de los alumnos de $2^{\circ}$ grado de primaria. Tesis de Grado. México: UNAM.

Ojeda-Castañeda, G. (1998). Hombre y Telecomunicaciones: Las estrategias politicas de la distancia. México, D. F., México: Universidad del Claustro de Sor Juana.

Pozo Sánchez, M. D. (2001). Los nuevos ambientes de aprendizaje. Material didáctico del Master en Educación a Distancia E-learning. Sevilla, España: Divulgación Dinámica.

Regil Vargas, L. (2005). Hipermedia: Medio, Lenguaje, Herramienta del Arte Digital. Revista Digital Universitaria. Publicaciones Digitales de la Universidad Nacional Autónoma de México.

Reguera, F. (2000). UOC: Tecnología al servicio de la enseñanza. Revista Net Conexion. Barcelona, España: Ed. Zinco Multimedia.

Royo, J. (2006). Diseño Digital. Ed. Paidos.

Solano Perez, K. (2001). Multimedia e Internet para el aprendizaje: Portal de aprendizaje interactivo para niños latinoamericanos. México.

Titone, R. (1968). Metodología didáctica. Madrid, España: Ediciones Rialp.

Valdés, J. C. (2005). Mediación pedagógica y las posibilidades educativas de las Nuevas Tecnologías. Una reflexión epistemológica desde la pedagogía. Tesis de Grado. México: UNAM.

Villafañe, J. y Mínguez, N. (1996). Principios de Teoría General de la Imagen. Madrid, España: Paraninfo.

Villarreal, D. (2004). Análisis de la comunicación educativa de la pedagogía en línea desde el enfoque de mediación pedagógica en el uso de nuevas tecnologías de la información y comunicación. Tesis. México: UNAM. 